\title{
Applying liquid chromatography-tandem mass spectrometry to assess endodontic sealer microleakage
}

André Luiz da Costa MICHELOTTO(a) João Cleverson GASPARETTO(b) Francinete Ramos CAMPOS ${ }^{(b)}$ Gilson Blitzkow SYDNEY(c) Roberto PONTAROLO(b)

(a) Universidade Tuiuti do Paraná - UTP, School of Dentistry, Department of Endodontics, Curitiba, PR, Brazil.

(b) Universidade Federal do Paraná - UFPR, Health Sciences, Department of Pharmacy, Curitiba, PR, Brazil.

(c) Universidade Federal do Paraná - UFPR, School of Dentistry, Department of Endodontics, Curitiba, PR, Brazil.

Declaration of Interests: The authors certify that they have no commercial or associative interest that represents a conflict of interest in connection with the manuscript.

Corresponding Author:

André Luiz da Costa Michelotto

E-mail: amichelotto@gmail.com

DOI: 10.1590/1807-3107BOR-2015.vol29.0100

Submitted: Jan 04, 2015

Accepted for publication: May 15, 2015

Last revision: Jul 06, 2015
Abstract: The objective of this study was to describe a new method for the quantitative analysis of a microleakage of endodontic filling materials. Forty extracted single-rooted teeth were randomly divided into three experimental groups. After root canal shaping, the experimental groups were filled using the lateral condensation technique with the Epiphany system (G1), with gutta-percha + Sealapex (G2), and with gutta-percha + AH Plus (G3). Each root was mounted on a modified leakage testing device, and caffeine solution was used as a tracer (2000 $\mathrm{ng} \mathrm{mL}^{-1}, \mathrm{pH}$ 6.0), applied in the coronal direction towards the tooth apex, creating a hydrostatic pressure of $2.55 \mathrm{kPa}$. Presence of caffeine in the receiving solution was measured after 10, 30, and 60 days, using high performance liquid chromatography-tandem mass spectrometry (HPLC-MS/MS). None of the groups presented microleakage at 10 days. At 30 days, G2 and G3 showed similar infiltration patterns (means: 16.0 and $13.9 \mathrm{ng} \mathrm{mL}^{-1}$, respectively), whereas G1 showed significantly higher values (mean: $105.2 \mathrm{ng} \mathrm{mL}^{-1}$ ). At 60 days, leakage values were $182.6 \mathrm{ng} \mathrm{mL}^{-1}$ for G1, $139.0 \mathrm{ng} \mathrm{mL}^{-1}$ for $\mathrm{G} 2$, and $53.5 \mathrm{ng} \mathrm{mL}^{-1}$ for G3. AH Plus showed the best sealing ability and HPLC-MS/MS showed high sensitivity and specificity for tracer quantification.

Keywords: Dental Leakage; Endodontics; Root Canal Filling Materials.

\section{Introduction}

The ultimate goal of endodontic therapy is to provide a root canal filling that allows impermeability of the root canal system, using a non-irritant material that stimulates periapical healing. Therefore, the sealing ability of endodontic filling materials is important to prevent (re)infection of the root canal by microorganism leakage. ${ }^{1}$

When new sealing materials or techniques emerge, studies should be performed to warrant their clinical application and to accurately assess their characteristics and properties, particularly their sealing ability. Several methods aimed at detecting leakage have already been described in the literature, such as the conductometric technique, ${ }^{2}$ fluid filtration, ${ }^{3,4}$ radioisotopes, ${ }^{5}$ bacterial penetration, ${ }^{6}$ the electrochemical test, ${ }^{7}$ and the use of dyes. ${ }^{8,9}$ However, all these methods have yielded controversial results, and have therefore been widely criticized. $7,8,10,11$ 
Some studies have presented improvements to leakage assessment methods. Chittoni et al. ${ }^{12}$ used back-scattered electron imaging to better delimit visualization of gaps in retrofilling materials, using a scanning electron microscope (SEM). Another technique proposed to assess long-term leakage uses an ultraviolet visible (UV-VIS) spectrophotometer and glucose as a tracer. ${ }^{13,14}$ However, the system was not able to measure the microleakage, because of the low sensitivity of the detector, capable of detecting tracers only at concentrations of $\mu \mathrm{g} \mathrm{mL}^{-1}$ or above. Thus, the improvement of currently available methods is extremely important, and technical modifications are often necessary to improve the reliability of the results.

The objective of this study was to describe a simple and rapid protocol to quantify the microleakage of filling materials using high performance liquid chromatography-tandem mass spectrometry (HPLC-MS/MS) and to assess how well the proposed method can detect very low concentrations of tracers.

\section{Methodology \\ Chemicals and reagents}

Ethylenediaminetetraacetic acid (EDTA), sodium azide, and standard solutions of caffeine (99.9\%) and theophylline $(99.9 \%)$ were purchased from Sigma-Aldrich (Saint Louis, USA). Acetonitrile was purchased from J.T. Baker Chemicals B.V. (Deventer, Netherlands), and ammonium formate from Acros Organics (Fair Lawn, USA). Ultra pure water was obtained using a Milli-Q purification system made by Millipore Corporation (Bedford, USA). The following fillings were obtained from Dentsply: $\mathrm{AH}$ Plus (Konstanz, Germany) and gutta-percha points (Ballaigues, Switzerland). Sealapex was purchased from SybronEndo (Orange, USA) and the Epiphany system from Pentron Clinical Technologies (Orange, USA). Epoxy resin (Poxipol) was obtained from Akapol S.A. (Buenos Aires, Argentina).

\section{Tooth selection and treatment}

Forty extracted, single-rooted well-preserved human lower premolars were selected from the tooth bank at the Universidade de São Paulo - USP. Absence of previous endodontic treatment was confirmed radiographically. The coronal portions of all teeth were removed, leaving the roots $12 \mathrm{~mm}$ in length. The specimens were hydrated by immersion in $0.9 \%$ saline solution for 72 hours. The research protocol was approved by the Ethics Committee of the Universidade Tuiuti do Paraná - UTP (protocol 000117/2008).

\section{Root canal preparation}

Canal debridement was performed using a \#15 K-Flexofile (Dentsply-Maillefer, Ballaigues, Switzerland). The root canal length was established by inserting a file into the canal until the tip became visible at the apical foramen. The working length was determined by subtracting $1 \mathrm{~mm}$ from this length. Root canal orifices were enlarged using the \#1, \#2 and \#3 Gates-Glidden drills (Dentsply-Maillefer, Ballaigues, Switzerland), and the canals were enlarged to file \#50, using the balanced force technique ${ }^{15}$ with K-Flexofiles; $2.5 \%$ sodium hypochlorite was used as the irrigant solution. A final irrigation was performed to eliminate any residual effects of the sodium hypochlorite, using $3 \mathrm{~mL}$ of $17 \%$ EDTA and distilled water for 1 minute. Apical patency was maintained using a \#15 K-Flexofile.

\section{Obturation}

Canals were dried using \#50 absorbent paper points. The teeth were filled using the lateral condensation technique. Specimens were randomly distributed into three experimental groups $(n=10$ each) and one negative control group $(n=10)$. The experimental groups were filled using the Epiphany system (G1), gutta-percha + Sealapex sealer (G2), and gutta-percha + AH Plus sealer (G3), respectively; all three sealers were prepared according to the manufacturer's instructions.

A \#40 file was used to pick up a measured amount of sealer $(20 \mathrm{~mL})$, determined by the use of a fixed-volume semiautomatic micropipette. Sealers were placed into the canals while rotating the teeth counterclockwise. A \#50 standardized Resilon point - Epiphany system (G1) or gutta-percha (G2/G3) master cone - was placed into the canal until the working length. Lateral condensation was achieved using six MF accessory cones and a blue finger spreader (Dentsply-Maillefer, Ballaigues, Switzerland). The roots of the three experimental 
groups were coated with two layers of nail varnish, except root canal orifices and apical foramina. The negative control group was filled with gutta-percha and AH Plus sealer, and was completely coated with two layers of nail varnish, including the root canal orifices and apical foramina.

All specimens were fixed on a wax plate for impermeabilization, and then stored in an aqueous solution containing $0.1 \%$ sodium azide $\left(\mathrm{NaN}_{3}\right)$ for 2 weeks.

\section{Measurement of sealing ability}

Each specimen was mounted on a modified leakage testing device described by $\mathrm{Xu}$ et al. ${ }^{13}$. In brief, the coronal portions of the specimens were placed in a silicone tube and fixed with a stainless steel wire. The system was adapted by cutting off one end of the Eppendorf tube and sealing the tube with epoxy resin rather than cyanoacrylate, as originally proposed. Each silicone tube containing a specimen was sealed with a rubber lid and then transferred to a sterile glass bottle containing $5.0 \mathrm{~mL}$ of $0.2 \%$ sodium azide (receiving solution) and 3,000 $\mathrm{ng} \mathrm{mL}^{-1}$ theophylline (internal standard, IS). The apical portion of the root was maintained in contact with the receiving solution. Then, a glass pipette $(34 \mathrm{~cm})$ containing $26 \mathrm{~cm}$ of a solution of caffeine $\left(2,000 \mathrm{ng} \mathrm{mL}^{-1}\right)$, sodium azide $(0.2 \%)$ and theophylline (IS, 3,000 $\mathrm{ng} \mathrm{mL}^{-1}$ ) was coupled to the upper part of the silicone tube containing the specimen, creating a hydrostatic pressure of $2.55 \mathrm{kPa}$ (Figure 1).

Leakage was determined by the amount of caffeine that reached the glass bottle (receiving solution) through the root canal after 10, 30, and 60 days. After each of these time periods, $1 \mathrm{~mL}$ of the receiving solution of each tube was collected for analysis, and the same amount was then replaced.

\section{HPLC-MS/MS analysis}

HPLC-MS/MS analysis was performed using an Agilent ${ }^{\circledR} 1100$ HPLC System (Agilent Technologies Inc., Wilmington, USA), consisting of a G1311A quaternary pump, a G1379A degasser, and a G1316A column oven connected to a CTC 2777 sample manager (Waters Corporation, Milford, USA). The system was coupled to an API 3200 triple quadrupole mass spectrometer

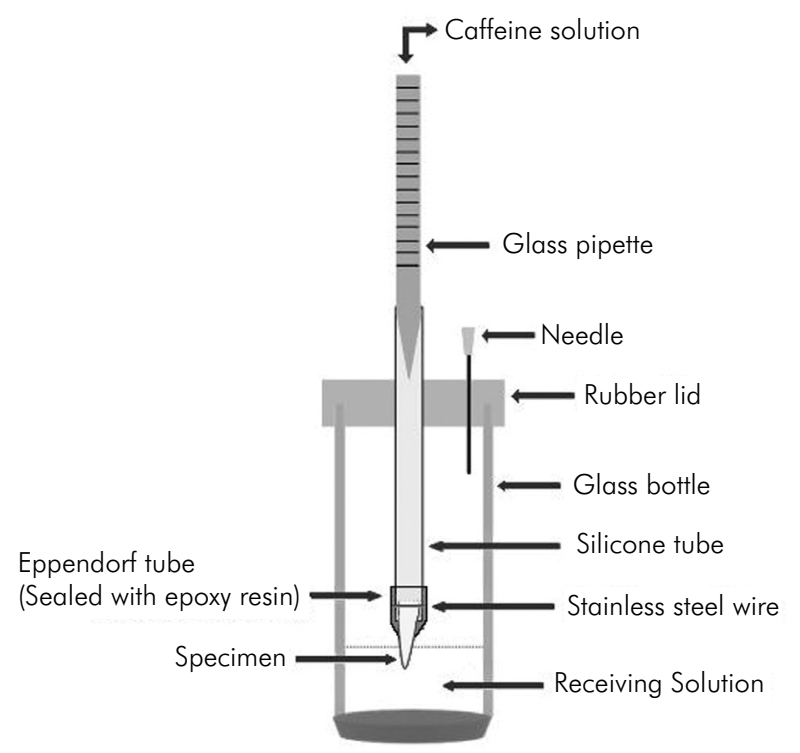

Figure 1. Modified leakage testing device.

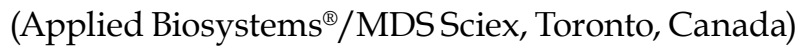
equipped with a Harvard 22 dual syringe pump (Harvard Apparatus, South Natick, USA), and an electrospray ionization (ESI) source operating in the positive ion mode.

Analyses were carried out on an XBridge C18 column (150 x $4.6 \mathrm{~mm}$ i.d., $5 \mathrm{~mm}$ particle size), connected to a security guard column $(10.0 \times 4.6 \mathrm{~mm}$ i.d., $5 \mathrm{~mm}$, Waters Corporation, Milford, USA) at room temperature. The mobile phase consisted of acetonitrile and water $(20: 80, v / v)$, containing $5 \mathrm{mM}$ of ammonium formate, in an isocratic elution system, at a flow rate of $0.3 \mathrm{~mL} \mathrm{~min}^{-1}$. The injection volume was $20 \mathrm{~mL}$. Data acquisition was performed using the Analyst 1.4.2 software (Applied Biosystems ${ }^{\circledast} /$ Sciex, Toronto, Canada).

Caffeine leakage quantification was performed in the positive ion mode by multiple reaction monitoring (MRM) assays. The following ion source parameters were used: source temperature, $450^{\circ} \mathrm{C}$; collision cell exit potential (CXP), $4.0 \mathrm{~V}$; declustering potential (DP), $46 \mathrm{~V}$; ion spray voltage, $5500 \mathrm{~V}$; collision energy (CE), $27 \mathrm{~V}$ for IS $\left(\mathrm{m} / z 181{ }^{\circledR} 124\right)$ and $25 \mathrm{~V}$ for caffeine $\left(\mathrm{m} / z 195{ }^{\circledR} 138\right)$; entrance potential (EP), $8.5 \mathrm{~V}$ for IS and $2.5 \mathrm{~V}$ for caffeine. Nebulizer gas (GS1), turbo heater gas (GS2), curtain gas (CUR), and collision gas (CAD) were set to 40,50, 18 and 4 psi, respectively. 
The ultra-high purity (UHP) nitrogen and the zero grade air used as curtain, nebulizer and collision gases were produced by a high-purity nitrogen generator (PEAK Scientific Instruments, Chicago, USA).

\section{Preparation of standard solutions}

Stock solutions of caffeine and theophylline (IS) were prepared separately in water/acetonitrile $(20: 80 \mathrm{v} / \mathrm{v})$ at concentrations of $200 \mu \mathrm{g} \mathrm{mL} \mathrm{L}^{-1}$ and $100 \mu \mathrm{g} \mathrm{mL}^{-1}$, respectively. All stock solutions were stored under refrigeration at $4^{\circ} \mathrm{C}$. Other standard solutions were prepared from this initial preparation, having different dilutions/concentrations, according to the experimental needs. All standard solutions were filtered using a Millex PVDF syringe filter $(11 \mathrm{~mm}, 0.45 \mu \mathrm{m}$, Millipore Corporation, Bedford, USA) before use.

\section{Sample quantification}

A calibration curve with eight concentration levels was constructed to determine the amount of caffeine infiltration. Standard solutions were prepared in triplicate, by mixing the stock solutions until reaching final concentrations of 10, 50, 100, 200, 600, 1,000, 1,400, and 1,800 $\mathrm{ng} \mathrm{mL}^{-1}$ of caffeine and $3,000 \mathrm{ng} \mathrm{mL}^{-1}$ of theophylline (IS) in each level. The calibration curve was generated to confirm the linear relationship between analyte/IS peak areas vs. analyte/IS concentrations. Slope, intercept and regression coefficient $(r)$ were calculated as regression parameters using weighted $(1 / x)$ linear regression.

\section{Limits of quantification}

A comparative analysis of the limit of quantification between the UV-VIS spectrophotometer (Agilent 8453) and HPLC-MS/MS was performed by assessing the triplicate standard solutions prepared by a decreasing caffeine concentration series. For the HPLC-MS/MS, the limit of detection was determined as the smallest peak at a signal-to-noise ratio of 10:1, and for UV-VIS, as the smallest signal detectable at $274 \mathrm{~nm}$.

\section{Statistical analysis}

Statistical analyses were performed using the OriginPro 8 software (OriginLab, Northampton, England). Overall differences between the groups (at 30 and 60 days) were assessed using one-way analysis of variance (ANOVA). The Tukey's test was applied to assess the pair-wise comparisons. Significance was set at $\mathrm{p}<0.05$.

\section{Results}

After 10, 30, and 60 days, $1 \mathrm{~mL}$ of the receiving solution of each group was collected and injected into the HPLC-MS/MS. The aliquots collected from the negative control group presented no caffeine leakage during the entire analysis period. Therefore, the seal system was considered effective and reliable for the assessment of a microleakage with the different sealer brands under investigation.

In regard to the overall investigation period, one-way ANOVA (Table 1) revealed differences between the experimental groups for leakage behavior $\left(p<1 \times 10^{-6}\right.$, correlating days, groups, and days vs. groups). Tukey's pair-wise comparisons (Table 1) demonstrated that at 30 days, G1 (Epiphany) had a leakage behavior different from that of G2 (Sealapex) and G3 (AH Plus) $(p=0.0001)$, which presented a similar leakage behavior $(p=0.9981)$. At 60 days, no group presented similar infiltration ( $p=0.0001)$, and maximum values were observed in G1 (182.61 $\left.\pm 14.85 \mathrm{ng} \mathrm{mL}^{-1}\right)$, followed by G2 (138.98 $\left.\pm 10.83 \mathrm{ng} \mathrm{mL}^{-1}\right)$ and G3 (53.52 $\left.\pm 3.87 \mathrm{ng} \mathrm{mL}^{-1}\right)$ (Table 2 and Figure 2).

The proposed method (HPLC-MS/MS) was able to detect very low tracer concentrations, and has therefore proven capable of assessing microleakage.

\section{Discussion}

Leakage is an important component in the assessment of root canal filling systems, and has been extensively studied using different methods. However, results vary depending on the method employed, creating serious concerns for reproducibility, and suggesting that a more critical analysis of the available models is needed. 7,8,11,16

Among the methods currently employed to determine leakage, the one described by $\mathrm{Xu}$ et al. ${ }^{13}$ has been preferred, because it uses glucose as a tracer, and allows continuous observer-independent measurements of a high number of specimens. However, the system (UV-VIS) detection efficiency was not adequate for making microleakage measurements, and some interfaces of the apparatus were sealed 
Table 1. One-way ANOVA analyses and Tukey's pairwise comparisons between groups: Epiphany (G1), Sealapex (G2), and AH Plus (G3) sealers.

\begin{tabular}{lcccccc}
\hline Days/Group & $30(G 1)$ & $30(G 2)$ & $30(G 3)$ & $60(G 1)$ & $60(G 2)$ & $60(G 3)$ \\
\hline $30(G 1)$ & & 0.000138 & 0.000138 & 0.000138 & 0.000143 & 0.000138 \\
$30(G 2)$ & 0.000138 & & 0.998181 & 0.000138 & 0.000138 & 0.000139 \\
$30(G 3)$ & 0.000138 & 0.998181 & & 0.000138 & 0.000138 & 0.000138 \\
$60(G 1)$ & 0.000138 & 0.000138 & 0.000138 & & 0.000138 & 0.000138 \\
$60(G 2)$ & 0.000143 & 0.000138 & 0.000138 & 0.000138 & 0.000138 \\
$60(G 3)$ & 0.000138 & 0.000139 & 0.000138 & 0.000138 & 0.000138 & \\
\hline
\end{tabular}

p-value with 95\% confidence level (Tukey's test).

One-way ANOVA correlations: days, < 1 $1 \times 10^{-6}$; groups, $<1 \times 10^{-6}$; days $\times$ groups: $<1 \times 10^{-6}$.

Table 2. Mean leakage values per group.

\begin{tabular}{lcc}
\hline \multirow{2}{*}{ Groups } & \multicolumn{2}{c}{ Mean $\left(\mathrm{ng} \mathrm{mL}^{-1}\right)$} \\
\cline { 2 - 3 } & 30 days & 60 days \\
\hline Negative control & $0.00 \pm 0.00$ & $0.00 \pm 0.00$ \\
Epiphany & $105.24 \pm 5.05$ & $182.61 \pm 14.85$ \\
Sealapex & $16.03 \pm 1.38$ & $138.98 \pm 10.83$ \\
AH Plus & $13.91 \pm 1.20$ & $53.52 \pm 3.87$ \\
\hline
\end{tabular}

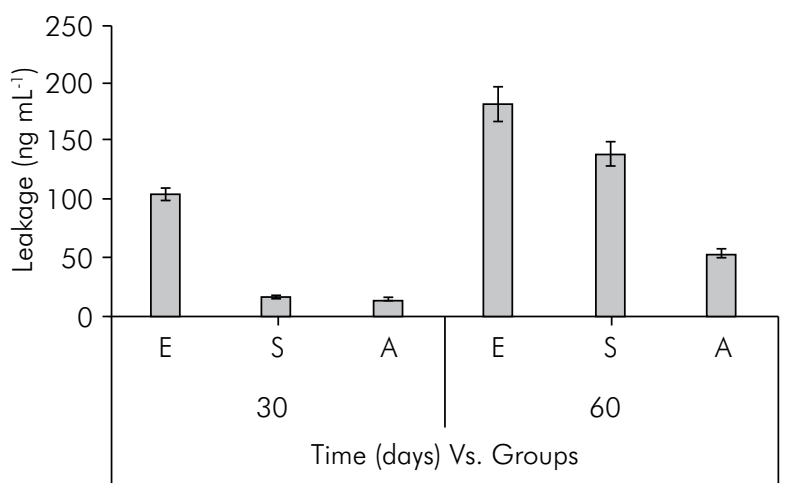

Figure 2. Leakage results obtained for Epiphany (G1), Sealapex (G2) and AH Plus (G3) sealers.

with cyanoacrylate, a material that has been widely criticized for failing to prevent leakage. .,17,18,19,20 $^{2}$

In this study, the first step was to reproduce the apparatus described by Xu et al. ${ }^{13}$, and then propose a more sensitive microleakage determination method based on this model. However, despite several attempts to seal the system using cyanoacrylate, infiltration of the tracer solution through the sealer could not be prevented. Thus, cyanoacrylate was considered unsuitable for use as a sealant material, and was replaced with epoxy resin (Figure 1). The proposed modification yielded a complete sealing of the system, during the entire analysis period, therefore achieving high reproducibility.

HPLC-MS/MS was then used to achieve effective leakage measurement. For comparison purposes, the limits of caffeine detection were assessed using the proposed method (HPLC-MS/MS) and UV-VIS, initially reported by $\mathrm{Xu}$ et $a l .{ }^{13}$ as a high sensitivity technique to detect tracers. The caffeine detection limit was 2,000 $\mathrm{ng} \mathrm{mL}^{-1}$ using UV-VIS and $10 \mathrm{ng} \mathrm{mL}^{-1}$, using HPLC-MS/MS. The relevance of the proposed technique is further confirmed by comparing our results with those of other studies, using UV-VIS. ${ }^{13,14,21,22,23,24,25,26,27,28,29}$ HPLC-MS/MS is able to detect concentrations at least 1,000 times lower. These data underscore the superiority of HPLC-MS/MS over UV-VIS detectors, and suggest that the new quantification method is appropriate for tracer detection, even at very low concentrations.

Adequate selection of tracers for use in microleakage analysis studies is also worthwhile mentioning, because the physical and chemical properties of the substance employed may influence the results. There is a consensus that tracers should have a low molecular weight, so that they can penetrate the root canal more easily. ${ }^{8,30}$ Glucose is an excellent choice, due to its low molecular weight and absence of reactive compounds. However, it has not shown adequate ionization for mass spectrometry, thus affecting the sensitivity of the results. In this study, caffeine was the first choice as a tracer, 
because it is easily ionized, is water soluble, and has a neutral $\mathrm{pH}$ (6.0) and a low molecular weight $(\mathrm{MW}=194 \mathrm{Da})$.

In summary, assessment of microleakage using HPLC-MS/MS in this study was considered effective, since the analysis of real samples showed no caffeine microleakage in any of the groups analyzed at 10 days. At 30 days, the AH Plus and Sealapex showed similar leakage behavior $(p=0.9981)$, with 10 times smaller infiltration values than those of Epiphany. Finally, at 60 days, significant differences were observed in leakage behavior in all three groups. AH Plus presented better sealing than the other two groups, and was therefore considered the most effective sealer.

\section{References}

1. Schilder H. Filling root canals in three dimensions. Dent Clin North Am. 1967 Nov:723-44.

2. Jacobsen PH, Von Fraunhofer JA. Assessment of microleakage using a conductimetric technique. J Dent Res. 1975 Jan-Feb;54(1):41-8.

3. Derkson GD, Pashley DH, Derkson ME. Microleakage measurement of selected restorative materials: a new in vitro method. J Prosthet Dent. 1986 Oct;56(4):435-40.

4. Ulusoy OI, Nayir Y, Çelik K, Yaman SD. Apical microleakage of different root canal sealers after use of maleic acid and EDTA as final irrigants. Braz Oral Res. 2014 Jan-Feb;28(1):1-6.

5. Haikel Y, Wittenmeyer W, Bateman G, Bentaleb A, Allemann C. A new method for the quantitative analysis of endodontic microleakage. J Endod. 1999 Mar;25(3):172-7.

6. De-Deus G, Murad CF, Reis CM, Gurgel-Filho E, Coutinho Filho T. Analysis of the sealing ability of different obturation techniques in oval-shaped canals: a study using a bacterial leakage model. Braz Oral Res. 2006 Jan-Mar;20(1):64-9.

7. Karagenc B, Gencoglu N, Ersoy M, Cansever G, Kulekci G. A comparison of four different microleakage tests for assessment of leakage of root canal fillings. Oral Surg Oral Med Oral Pathol Oral Radiol Endod. 2006 Jul;102(1):110-3.

8. Wu MK, Wesselink PR. Endodontic leakage studies reconsidered. Part I. Methodology, application and relevance. Int Endod J. 1993 Jan;26(1):37-43.

9. Bodrumlu E, Parlak E, Bodrumlu EH. The effect of irrigation solutions on the apical sealing ability in different root canal sealers. Braz Oral Res. 2010 Apr-Jun;24(2):165-9.

10. Pommel L, Jacquot B, Camps J. Lack of correlation among three methods for evaluation of apical leakage. J Endod. 2001 May;27(5):347-50.

\section{Conclusion}

The HPLC-MS/MS technique employed in this study showed excellent linearity and higher tracing ability, compared with other systems reported in the literature, insofar as a low detection limit $\left(10 \mathrm{ng} \mathrm{mL}^{-1}\right)$ was achieved for the tracing agent. The new method was considered adequate for the quantitative assessment of a microleakage in filling materials, and caffeine proved to be an excellent choice for use as a tracer. The AH Plus sealer showed the best sealing ability.

\section{Acknowledgments}

The authors gratefully acknowledge Dr. Antônio Carlos Bombana (in memorian) for his contribution in this research.

11. Camps J, Pashley D. Reliability of the dye penetration studies. J Endod. 2003 Sep;29(9):592-4.

12. Chittoni SB, Martini T, Wagner MH, Da Rosa RA, Cavenago $\mathrm{BC}$, Duarte MA, et al. Back-scattered electron imaging for leakage analysis of four retrofilling materials. Microsc Res Tech. 2012 Jun;75(6):796-800.

13. Xu Q, Fan MW, Fan B, Cheung GS, Hu HL. A new quantitative method using glucose for analysis of endodontic leakage. Oral Surg Oral Med Oral Pathol Oral Radiol Endod. 2005 Jan;99(1):107-11.

14. Shemesh $\mathrm{H}, \mathrm{Wu} \mathrm{MK}$, Wesselink PR. Leakage along apical root fillings with and without smear layer using two different leakage models: a two-month longitudinal ex vivo study. Int Endod J. 2006 Dec;39(12):968-76.

15. Roane JB, Sabala CL, Duncanson MG, Jr. The "balanced force" concept for instrumentation of curved canals. J Endod. 1985 May;11(5):203-11.

16. Barthel CR, Moshonov J, Shuping G, Orstavik D. Bacterial leakage versus dye leakage in obturated root canals. Int Endod J. 1999 Sep;32(5):370-5.

17. Anderson RW, Powell BJ, Pashley DH. Microleakage of three temporary endodontic restorations. J Endod. 1988 Oct;14(10):497-501.

18. Fogel HM. Microleakage of posts used to restore endodontically treated teeth. J Endod. 1995 Jul;21(7):376-9.

19. Trope $M$, Chow E, Nissan R. In vitro endotoxin penetration of coronally unsealed endodontically treated teeth. Endod Dent Traumatol. 1995 Apr;11(2):90-4.

20. Forte SG, Hauser MJ, Hahn C, Hartwell GR. Microleakage of super-EBA with and without finishing as determined by the fluid filtration method. J Endod. 1998 Dec;24(12):799-801. 
21. Kaya BU, Kececi AD, Belli S. Evaluation of the sealing ability of gutta-percha and thermoplastic synthetic polymer-based systems along the root canals through the glucose penetration model. Oral Surg Oral Med Oral Pathol Oral Radiol Endod. 2007 Dec;104(6):e66-73.

22. Xu Q, Ling J, Cheung GS, Hu Y. A quantitative evaluation of sealing ability of 4 obturation techniques by using a glucose leakage test. Oral Surg Oral Med Oral Pathol Oral Radiol Endod. 2007 Oct;104(4):e109-13.

23. Zou L, Liu J, Yin SH, Tan J, Wang FM, Li W, et al. Effect of placement of calcium sulphate when used for the repair of furcation perforations on the seal produced by a resin-based material. Int Endod J. 2007 Feb;40(2):100-5.

24. Sluis LW, Shemesh H, Wu MK, Wesselink PR. An evaluation of the influence of passive ultrasonic irrigation on the seal of root canal fillings. Int Endod J. 2007 May;40(5):356-61.

25. De-Deus G, Soares J, Leal F, Luna AS, Fidel S, Fidel RA. Similar glucose leakage pattern on smear-covered,
EDTA-treated and BioPure MTAD-treated dentin. J Endod. 2008 Apr;34(4):459-62.

26. Ozok AR, van der Sluis LW, Wu MK, Wesselink PR. Sealing ability of a new polydimethylsiloxane-based root canal filling material. J Endod. 2008 Feb;34(2):204-7.

27. Souza EM, Wu MK, Shemesh H, Bonetti-Filho I, Wesselink PR. Comparability of results from two leakage models. Oral Surg Oral Med Oral Pathol Oral Radiol Endod. 2008 Feb;106(2):309-13.

28. Karapinar-Kazandag M, Tanalp J, Bayrak OF, Sunay H, Bayirli G. Microleakage of various root filling systems by glucose filtration analysis. Oral Surg Oral Med Oral Pathol Oral Radiol Endod. 2010 Jun;109(6):e96-102.

29. Kececi AD, Kaya BU, Belli S. Corono-apical leakage of various root filling materials using two different penetration models-A 3-month study. J Biomed Mater Res B Appl Biomater. 2010 Jan;92(1):261-7.

30. Kersten HW, Moorer WR. Particles and molecules in endodontic leakage. Int Endod J. 1989 May;22(3):118-24. 